\title{
Didática e História Escolar: Dimensões Disciplinares e Culturais.
}

\author{
Didactic and School History: Disciplinary and Cultural Dimensions.
}

\section{Maria Aparecida Leopoldino'}

\section{RESUMO}

O artigo objetiva refletir sobre os nexos que envolvem a Didática e a história escolar por meio de duas dimensõesque marcam sua historicidade: a disciplinar e a cultural. O intento com essa reflexão é enfatizar as condições históricas da disciplinarização desse saber balizadas pela crença na ideia de progresso e civilização que instituíram uma memória social ainda presente como continuidade dos problemas e mazelas do ensino de História escolar na sociedade brasileira e como tais dimensões envolvem a história escolare ecoa nas investigações sobre o ensino de História em diferentes direções analíticas no debate sobre a Didática da História. Em seu desdobramento, indica que a Didática da História se pergunte, fundamentalmente, sobre o espaço reservado a uma História e scolar crítica em um contexto reprodutivo de uma história tradicional permanente na cultura escolar como parte de seu universo teórico, conceitual e prático sobre o ensino e a aprendizagem da história escolar.

Palavras-chave: Educação escolar. Ensino de História. Didática. Formação de professores.

\begin{abstract}
The article aims to reflect on the nexus involving didacticand teaching of history through two dimensions that mark their historicity: disciplinary and cultural. The intent with this reflections is to emphasize the historical conditions this know buoyed by belief in the notion of progress and civilization that established a social memory still present as a continuation of the problems of the teaching of history in brazilian society and as such dimensions involve the teaching of history and echoes in the investigation of the teaching of history in different directions in analytical discussion on the didactic of history. Its unfolding indicates that the teaching of history if ask fundamentally about spotreservedfor a teaching of history critical in a context of a reproductive history permanent school culture traditional their theoretical, conceptual and practical universe on the teaching and learning of history.
\end{abstract}

Keyword: Education. Teaching of history. Didactics. Teacher training.

1 Professora Associada do Departamento de Teoria e Prática da Educação da Universidade Estadual de Maringá; Atua nas disciplinas de Didática para o ensino de História e Metodologia e prática do ensino de História. Doutorado em Educação. Programa: Educação, Política, Sociedade da Pontifícia Universidade Católica de São Paulo. 
'Papai, então me explica para que serve a história'. Assim um garoto, de quem gosto muito, interrogava há poucos anos um pai historiador. (Marc Bloch, 2001).

A História escolar tem-se caracterizado, desde o século XIX, como uma disciplina que realiza a aprendizagem de conhecimentos sobre o passado das sociedades humanas. Passado compreendido como objeto de uma grande coleção de acontecimentos, de fatos que parecem se colocar acima e de modo superior em relação ao intérprete, ao historiador, ao professor e aos alunos. Para o professor, um passado que pode ser narrado com exatidão e coerência cronológica, e para o aluno, um conjunto de deveres cotidianos que lhe ajuda a reter na memória uma cronologia dos fatos considerados mais importantes no enredo da evolução dos acontecimentos civilizadores a reboque do contexto europeu.

Tal perspectiva de ensino, no entanto, não se realizou/realiza de forma harmoniosa na medida em que críticas aos seus métodos e fundamentos teóricos estiveram também presentes no debate sobre "como" e o "o que" ensinar do passado, desde meados do século XX no cenário brasileiro. Mais recentemente, apontamentos sobre essa prática pedagógica de "transmissão" de conteúdos organizados em uma sistematização de linhagem historiográfica francesa ${ }^{2}$ trouxeram para a discussão pedagógica, sobre a organização de saberes históricos pela cultura escolar, a importância de uma didática específica para a construção de requisitos, recursos e orientações teóricas específicas sobre operações cognitivas no processo escolar de construção de saberes históricos que possam superar as mazelas produzidas por um ensino de História de abordagem eurocêntrica. Ou seja, acolhendo contribuições teóricas de autores internacionais, coloca-se em pauta a necessidade de uma história escolar que possibilite a produção de um saber capaz de promover a reflexão de tempora lidades diversas, de diferentes escalas de análises, de uma sequência didática fundamentada na problematização de unidades temáticas, uma prática pedagógica centrada nas diferenciações de narrativas historiográficas dos textos didáticos objetivando uma perspectiva crítica do mundo contemporâneo.

A importância que tais discussões, sobre os processos de ensino e de aprendizagem, ganharam nas últimas décadas do século $\mathrm{XX}$ no Brasil demandas para a ampliação das pesquisas sobre a Didática da História. Nos trabalhos de Cerri (2010), Assis (2010) e Lima (2014), a dimensão disciplinar e cultural que envolve a história escolar ecoa nas investigações sobre o ensino de História em diferentes direções analíticas no debate sobre a Didática da História.

2Cristalização da história política linear e eurocêntrica dividida em: "antiga", "medieval", "moderna" "e "contemporânea", o quadripartismo apontado por Jean Chesneuax (1994). 
Dentre as várias questões que são latentes encontra-se a discussão sobre o que seria a Didática da História, como ela organiza seu universo teórico, conceitual e prático sobre o ensino e a aprendizagem da história escolar. O aprendizado no ensino de escolar recebe atenção específica com vistas à elaboração teórica de processos e ações sistematizadas que possam resultar na aprendizagem de especificidades conceituais e sua referência científica, numa perspectiva de ensino crítico.

Trabalhos sobre a Didática da História se perguntam, fundamentalmente, sobre o espaço reservado a uma História escolar crítica em um contexto reprodutivo de uma história tradicional permanente na cultura escolar. Ou seja, indaga-se sobre as possibilidades de se produzir uma aprendizagem no qual a história social torne-se orientação cultural da vida prática e leitura da experiência coletiva e individual dos atores sociais.

Ao tratar desta questão, o artigo pontua duas dimensões deste saber escolar que, como se entende, estão no centro das diretrizes que orientam a Didática da História como campo disciplinar. Trata-se da dimensão disciplinar da história escolar e da dimensão cultural que a envolve e possibilita definir a complexidade de suas referências - historiografia acadêmica, história escolar, usos públicos da história - entendidas como expressões da cultura histórica da sociedade, conforme Le Goff (1996).

\section{História escolar: disciplinarização e usos do passado}

Parece correto afirmar que, entre os estudiosos da Didática da História, o elemento norteador da sua preocupação teórica e metodológica é a investigação de como se realiza o aprendizado histórico e de como é possível ensinar sobre o passado em situação escolar. Seu objeto, portanto, denota uma preocupação com a dimensão disciplinar da história que se expressa como saber necessário no contexto institucional dos sistemas educativos que se constituíram e são constituídos por meio de interesses político-econômicos e de certas práticas socioculturais no poder.

Já é bem conhecido que tais interesses resultaram em um processo de construção de representações sobre o passado vinculadas aos contornos políticos e culturais das sociedades que, no século XIX, elaboravam um amplo repertório simbólico que justificassem a invenção do Estado nacional. Nesse trajeto, a afirmação da história como disciplina escolar conheceu um caminho de disciplinarização que se justificou pelo uso social que faria do passado no espaço e tempo escolares. Como se sabe, não foi qualquer história que se afirmou como conteúdo nos programas escolares, mas aquela que fez do passado um ensinamento "útil" 
para o tempo presente. Sua finalidade, portanto, se vinculou a forma como a sociedade que a criou lidava com o passado no tempo presente. Discussão clássica que se fez/faz entre os conteúdos e o modo de ensinar que não pode ser vista apenas como uma questão de formalidade pedagógica, mas como elementos que compõem a cultura histórica da época.

Sobre isso, importa perceber que as condições históricas da disciplinarização desse saber foram balizadas pela crença na ideia de que progresso e civilização ${ }^{3}$ seriam um dado inerente da experiência social europeia válida para todas as sociedades, inclusive a brasileira. Os fundadores do Instituto Histórico Geográfico Brasileiro (IHGB), letrados que vivera m no tempo da independência, orientaram a consecução das tarefas de "coligir, metodizar e publicar os documentos necessários para a escrita da história do Brasil" (BARBOSA, 1839, p.1819) o que significou construir os alicerces, o legado e a opção de como se deveria escrever o passado.

Nunca é demais lembrar que, nesse trajeto, a crença na ideia de progresso e civilização marcou o olhar sobre a formação da nacionalidade brasileira. Por meio de sua escrita, a formação da nacionalidade esteve liga da ao passa do da coloniza ção portuguesa, condutora da gênese civilizatória da nação, que reuniu num território as "raças" formadoras do "povo brasileiro".

Por meio dos compêndios escolares de História se reproduziu o discurso das "três raças" que foi apresentado pelo bávaro Karl Friederich Phillipe von Martius ao IHGB em 1843, por intermédio de seu trabalho intitulado Como se deve escrever a História do Brasil, premiado pela instituição naquele mesmo ano. A dissertação tratava de indicar ao futuro historiador do Brasil os fatos que deveriam ser levados em conta ao escrever a História da Pátria. Por intermédio da tese de Martius desenvolveu-se uma historiografia didática que forneceu certa compreensão sobre como ver o passado, o papel e o lugar social ocupado pelas etnias na formação social brasileira.

No tópico I, "Idéias Gerais sobre a História do Brasil", Martius (1982, p.87) anuncia que quem se encarregasse de escrever a História do Brasil:

[...] jamais deverá perder de vista quais os elementos que aí concorrerão para o desenvolvimento do homem. São porém estes elementos de natureza muito diversa, tendo para a formação do homem convergido de um modo particular três raças, a saber: a de côr de cobre ou americana, a

3 Norbert Elias (2001, p.23-26.) sugere que o conceito de civilização "expressa a consciência que o Ocidente tem de si mesmo, pois o termo condensa tudo em que a sociedade ocidental se julga superior a sociedades antigas ou a sociedades contemporâneas normalmente entendidas como atrasadas. Assim, o conceito descreve como a sociedade ocidental representa o que lhe é especial e distintivo das demais e o que lhe orgulha: o nível de sua tecnologia, seus hábitos, o nível de desenvolvimento de sua cultura científica". 
branca ou caucasiana, e enfim a preta ou etiópica. Do encontro, da mescla, das relações mútuas e mudanças dessas três raças, formou-se a atual população, cuja história por isso mesmo tem um cunho muito particular.

Nesses princípios desenvolvidos por Martius enraizar-se-ão as explicações para a população nacional. A partir dessas ideias gerais, ele segue informando sobre as "raças"e suas contribuições para a História do Brasil. Inicialmente trata dos índios (a raça de cor de cobre). Para Martius (1982, p. 190), o historiador do Brasil deveria:

[...] investigar minuciosamente a vida e as histórias do desenvolvimento aborígenes americanos; e estendendo as suas investigações além do tempo da conquista, prescrutinará a história dos habitantes primitivos do Brasil, história que por ora não dividida em épocas distintas, nem oferecendo monumentos visíveis, ainda está envolta em obscuridade, mas que por esta mesma razão excita sumamente a nossa curiosidade.

Isso porque:

Só depois de haver estabelecido um juízo certo sôbre a natureza primitiva dos autóctonos brasileiros, poder-se-á continuar a mostrar, como se formou o seu estado moral e físico por suas relações com os emigrantes; em que êstesinfluiram por leis e comércio, e comunicação, sôbre os índios, e qual a parte que toca os boçais filhos da terra no desenvolvimento das relações sociais dos portuguêses emigrados. (MARTIUS, 1982, p.190).

Depois é a vez do elemento português (de cor branca). Esse se mostra no centro do "Descobrimento" e desenvolvimento da História do Brasil, na análise de Martius. Ao referirse ao português, a busca é sempre por mostrar como ocorreram a constituição e o desenvolvimento natural do Brasil, sendo esse elemento o principal veiculador de todo o processo de "descobrimento" do território nacional. 
Quando os portuguêses descobriram o Brasil, e nêle se estabeleceram, acharam os indígenas proporcionalmente em tão diminuto número e profundo aviltamento, que nas suas recem-fundadas colônias podiam desenvolver e estender-se quase sem importar-se dos autôctonos. Êstes exerceram sôbre os colonos uma influência negativa tão somente por quanto só os forçaram a acautelar-se contra as invasões hostis, e por isso criaram uma instituição singular de defesa, o Sistema das milícias. [...] vemos que a posição guerreira, em que se colocou o colono português para com o índio, contribuiu muito para a rápida descoberta do interior do país, como igualmente para a extensão do domínio português. (MARTIUS, 1982, p. 194).

Toda a ação do português contribuiu para o processo de descobrimento e colonização primitiva do Brasil. Essa que não pode ser compreendida, segundo o autor, senão em seu nexo com as façanhas marítimas, comerciais e guerreiras dos portugueses, "[...] que de modo algum pode ser considerado fato isolado na história dêsse povo ativo, e que sua importância e relações com o resto da Europa está na mesma linha com as emprêsas dos portuguêses" (MARTIUS, 1982, p.194). Na análise do naturalista transparece a ideia de que a História do Brasil deve estar em constante relação com a História Universal que, no conjunto, apresentaria os atributos da "modernidade" e do "progresso", inerentes da ideia de superioridade das nações europeias, prova da a scendência do homem branco europeu.

O historiógrafo do Brasil ver-se-á arrastado por tais observações a jamais perder de vista na história da colonização do Brasil, e do seu desenvolvimento civil e legislativo (que acompanhava aquela ao mesmo passo), os movimentos do comércio universal de então, e incorporá-los mais ou menos extensamente à sua história [...]. Assim, por exemplo, está a história do descobrimento do Brasil intimamenteligada com a história comercial de madeira índia chamada japan, que vulgarmente conhecida debaixo do nome de pau brasil, legnobrasilo, bresil, etc., foi a causa principal de dar-se à Terra de Santa Cruz o nome de Terra do Brasil. Também a história e movimento mercantil dos metais e pedras preciosas têm as mais estreitas relações com a história do Brasil, e finalmente a das plantas tropicais úteis, conhecidas na Europa depois da descoberta do Novo Mundo, jámais poderá ser separada da história da colonização do Brasil. (MARTIUS, 1982, p. 195-196). 
Quanto a "raça africana", para o autor, seria importante para o historiador indagar a condição dos negros importados, seus costumes, suas opiniões civis, seus conhecimentos naturais, preconceitos e superstições, os "defeitos e virtudes próprias à sua raça em geral", se quiser demonstrar como tudo reagiu sobre o Brasil.

Sendo a África visitada pelos portuguêses antes da descoberta do Brasil, e tirando eles dêste país grandes vantagens comerciais, é fora de dúvida que já naquele período influia nos costumes o desenvolvimento de Portugal. Por este motivo devemos analisar as circunstâncias das colônias portuguêsas na África, de tôdas as quais se trafica em escravatura para o Brasil, dever-se-á mostrar que movimento imprimiam na indústria, agricultura e o comércio das colônias africanas para com as do Brasil, e vice-versa. (MARTIUS, 1982, p. 201).

Bem fundamentado em fontes criteriosas ${ }^{4}$, o historiador do Brasil deveria investigar todos os fatores sociais, econômicos, climáticos, políticos, geográficos, culturais, da composição do "povo" e, por consequência, de sua nacionalidade. Numa palavra:

Nunca por tanto o historiador da Terra de Santa Cruz há de perder de vista que a sua tarefa abrange os mais grandiosos elementos; que não lhe compete tão somente descrever o desenvolvimento de um só povo, circunscrito em estreitos limites, mas sim de uma nação cuja crise e mescla atuais pertencem à história universal, que ainda se acha no meio de seu desenvolvimento superior. Possa ele não reconhecer em tão singular conjunção de diferentes elementos algum acontecimento desfavorável, mas sim a conjuntura mais feliz e mais importante no sentido da mais pura filantropia. (MARTIUS, 1982, p. 201)

O compromisso do historiador com sua pátria, segundo Martius, era o desenvolvimento de uma História da Nação vista como integrante do universo europeu, que pudesse difundir sentimentos e pensamentos do mais nobre patriotismo entre os nacionais (TOLEDO, 2016). Uma obra histórica, segundo a opinião do autor, deveria ter igualmente "a tendência de

4 Pode-se dizer que, possivelmente, Martius se referia a trabalhos de cronistas, narrativas de viajantes e de textos divulgados pelo Instituto Histórico e Geográfico Brasileiro que circulavam entre os letrados à ép oca. 
despertar e reanimar em seus leitores brasileiros amor da pátria, coragem, constância, fidelidade, prudência, todas as virtudes cívicas" (MARTIUS, 1982, p. 201).

Essa temática tornou-se um desafio enfrentado pelo IHGB que, após o concurso em que Martius teve sua tese premiada, nove anos depois (1854) apoiou a publicação da obra do membro institucional Francisco Adolfo de Varnhagen, História Geral do Brasil.

Em sua obra, Varnhagen procura encontrar entre as três "raças" o "verdadeiro representante histórico da nacionalidade". Conforme segue, Varnhagen (1854, p. ix):

Bem meditadas todas as questões acerca dos índios, quer em relação a eles unicamente, quer com respeito aos colonos, quer à partilha de glória que lhes deve caber na história de cada uma das nações americanas, podem elas reduzir-se nos seguintes pontos:

1. Eram os que percorriam o nosso território, à chegada dos cristãos europeus, os seus legítimos donos?

2. Viviam, independentemente da falta do ferro $e$ do conhecimento da verdadeira religião, em estado social invejável?

3. Esse estado melhoraria, sem o influxo externo que mandou a Providencia por meio do cristianismo?

4. Havia meios de os reduzir e amansar, sem empregar a coação pela força?

5. Houve grandes excessos de abuso nos meios empregados para essas reduções?

6. Dos três principais elementos de povoação, índio, branco e negro, que concorrerem ao desenvolvimento de quase todos os países da América, qual predomina hoje no nosso?

7. Quando se apresentem discordes ou em travada luta estes três elementos no passado, qual deles devemos supor representante histórico da nacionalidade hoje? 
Para Varnhagen (1854, p. xxv) a questão já estava bem definida, sem meias palavras conclui:

Quereis saber o que é a nação brasileira? Olhai para o próprio brasão d'armas que a simboliza. Nele vereis a esfera armilar, significando a origem da dinastia e a do Estado, e nele vereis também a cruz da ordem de Cristo, que representa por si só a história da civilização do país. E isto não escrito neste ou naquele idioma, ininteligível aos demais povos; mas apregoados na bela linguagem heráldica, composta de hieroglíficos, que constituem, nos feitos históricos, uma espécie de pasigrafia ao alcance de todas as nações civilizadas.

Ao construir tal narrativa, Varnhagen não considera a participação dos grupos sociais negros e índios - na construção da nação. A representação da nacionalidade está na constituição simbólica do Estado e, sua história, nas ações do Estado em organizar o povo para se conduzir ao "estágio de civilização" que se desejava.

Tais ideias, fundamentalmente aquela presente na obra de Varnhagen, serviram de sustentação para a composição de compêndios didáticos e ensinaram a várias gerações de brasileiros "o que era o Brasil e o que era ser brasileiro". Joaquim Manoel de Macedo, ocupando a cátedra de Corografia e História do Brasil no Colégio Pedro II em 1860, constrói um Brasil que nasce da descoberta marítima de Pedro Álvares Cabral, organizado em capitanias hereditárias e composto pelas "raças" do negro, branco e do índio.A referência central é o fato que localiza o momento inaugural do Brasil, conhecido como mito fundador, o "Descobrimento" em 1500. A criação deste fato, monumentalizado na escrita de Macedo, em seu compêndio Lições de História do Brasil de 1861, inaugura uma "identidade coletiva" e um projeto de "nação" para a sociedade brasileira.

As marcas de uma historiografia didática como princípio de canonização das demarcações de tais temporalidades, espacialidades e seleção de conteúdos eurocêntricos enfatizaram o papel decisivo da disciplina na construção de uma memória social por intermédio da elaboração dos programas de estudos, dos manuais e compêndios, autoresprofessores e suas obras, bem como as instituições de ensino que participaram deste trajeto 5 . Tais compêndios tornaram-se "construtores de identidades" (GASPARELLO, 2004), e em um dos "lugares de memória" da história do Brasil, fazendo "uso do passado" no que diz respeito à experiência histórica brasileira.

Tem-se aqui o eixo da problemática que envolve história, memória e disciplina rização da história escolar que interesse ressaltar. Especificamente porque, se é certo afirmar com

\footnotetext{
${ }^{5}$ Para conhecer outros compêndios e manuais do período ver: Toledo (2012).
} 
Hobsbawm e Ranger (1997, p.21) que toda tradição inventada "utiliza a história como legitimadora das ações e como cimento da coesão grupal", o grupo responsável pela criação do passado certamente valoriza certas utilizações da memória e inibe outras em referência ao passado de um "povo". O sentido da tradição vinculada a disciplinarização da história relaciona-se, portanto, a

Um mundo onde existe um mecanismo pelo qual a história singular de cada ente pode ser religada à história social do grupo a que pertence. Mais ainda, um mundo onde a história individual de cada um adquire uma boa parte do seu sentido quando, e apenas quando, religada à história do grupo. Ou seja, um mundo onde a identidade não pode se separar da memória, e vice-versa. (CASTRO, 2005, p.14-15).

Por meios desses nexos é possível reconhecer a relação da história escolar com os usos do passado pelo que ela seleciona, privilegia, como pelo que apaga; pelo que celebra ou omite, pelo que repete ano a ano, monumentalizando o que recolhe do passado a ser ensinado.A disciplinarização da história proclama a identidade e soberania do país, uma tradição a ser lembrada pelos cidadãos por meio de símbolos criados. Ao inventar uma bandeira nacional, um hino e as armas nacionais, simbolicamente também se inventa um passado, narrado por uma história considerada comum, legitimamente representante de todos que compõe a sociedade. A disciplinarização da história produz, enfim, uma memória social, faz usos do passado no qual estão justificados, de antemão, os posicionamentos dos grupos sociais na arena política e social.

Assinalar que as sociedades conservam sua memória por meio do ensino de História significa afirmar que a narrativa dos livros didáticos guarda uma memória histórica construída por intelectuais/professores pertencentes a grupos sociais, instituições e lugares que legitimam determinada visão do passado. Sujeitos que estão comprometidos com a complexa questão da "identidade" e à perspectiva de um ensino historicamente voltado para a legitimação da realidade social.

Nesse sentido, considerar a importância das características do "coletivo" para a constituição do "indivíduo", reconhecendo que os seres sociais recordam e esquecem conforme os "quadros" de memória (HALBWACHS, 2006) produz inquietações sobre o sentido do conhecimento histórico que "[...] parece ter se transformado na memória deste mesmo progresso" (GUIMARÃES, 1998, p. 8), cuja finalidade prioritária seria o avanço social para um estado supostamente mais evoluído e civilizado de sua nação. 
A inquietação que ronda as pesquisas sobre o ensino de História atualmente, em boa medida, refere-se a esta constatação sobre o aspecto disciplinar da história escolar. Inquieta perceber o papel da história escolar nessa análise sobre as relações humanas com o passado, suas tradições e o fenômeno de tornar-se a própria tradição, realizada, não raro, por meio de conflitos e de lutas pela memória social e pelos monumentos presentes que os grupos de que participam lhes disponibilizam por meio da comunicação e escrita. A memória social está alimentada, ainda hoje, pela monumentalização feita nas artes e por meio da história escrita no Império. De acordo com essa tradição, as narrativas da "descoberta", consoante a memória nacional e do desenvolvimento político da nação, continuam a prevalecer em uma linha do tempo evolucionista, que justifica a colonização europeia e a subjugação dos nativos e africanos, visando localizar o progresso e a civilização em cada período da história política nacional.

Reconhecendo que o ofício do historiador e do professor de História está envolvido nesse processo de interpretação das tradições onde se realiza o poder político e seus interesses pelo passado, luta-se por um ensino em que dilemas sociais, políticos e culturais que envolvem a história brasileira estejam presentes como temas de reflexão, como conteúdo no ensino de História escolar. Revendo a tradição inventada e lançando luzes sobre as memórias apagadas, discutindo conceitos que foram cristalizados na historiografia didática que remetem às práticas coercivas de grupos sociais posicionados de forma diferente no âmbito cultural da sociedade bem como de conceitos que remetem a direitos e obrigações universais quanto à natureza dos valores como "lealdade", "patriotismo", "espírito escolar", entre outros.

O estudo da disciplinarização esclarece parte da cultura histórica em que a sociedade brasileira está imersa, e, ainda, que o que se preservou não é "A História", mas que memórias foram apagadas, mitos foram criados, preconceitos foram produzidos, desigualdades sociais justificadas, e que, os professores estão envolvidos, sejam quais forem seus objetivos pedagógicos, neste processo de construção da memória social.

A Didática da História deve, como se entende, dialogar com esse aspecto da dimensão disciplinar que aparece como permanência da tradição que utiliza a história escolar como legitimadora das ações e coesão de grupos politicamente assentados no poder. Daí a importância de avançar na discussão para o segundo aspecto proposto neste texto, as dimensões culturais.

\section{Cultura histórica e história escolar: o interstício da memória}

Outro elemento importante, que se vincula ao problema a nteriormente apontado, é a estreita relação que a história escolar tece com os aspectos culturais da sociedade. Reconhecer 
que a história escolar se tornou parte dos conhecimentos sobre o passado da nação sugere que o que se sabe sobre a vida social brasileira não corresponde a "totalidade" (ou o que mais importa)do que foi realmente experienciado pelos diferentes grupos sociais, mas, sim, aquilo que foi selecionado, escrito, narrado, memorizado, monumentalizado nos espaços sociais por quem estava encarregado de fazê-lo. De modo que pensar a relação da história com a memória passa a ser crucial para o entendimento e a crítica da história ensinada.

Os estudos sobre a relação História e Memória partem do suposto de que a visão tradicional desta relação, "na qual a memória reflete o que aconteceu na verdade e a história reflete a memória, parece hoje demasiado simples". Tanto a história quanto a memória passaram a revelar-se cada vez mais complexas, como afirma Burke (2000, p.69):

Lembrar o passado e escrever sobre ele não mais parecem atividades inocentes que outrora se julgava que fossem. Nem as memórias nem as histórias parecem mais ser objetivas. Nos dois casos, os historiadores aprendem a levar em conta a seleção consciente ou inconsciente, a interpretação e a distorção. Nos dois casos, passam a ver o processo de seleção, interpretação e distorção como condicionado, ou pelo menos influenciado, por grupos sociais. Não é obra de indivíduos isolados.

A partir de tal constatação, o tema da memória passa, no século XX, a ser estudado com maior dedicação por historiadores contemporâneos, confiantes na comprovação de sua dimensão social. A contribuição de Pierre Nora (1993) e Jacques Le Goff (1996) trouxe para o campo da investigação sobre o ensino de História e da História ensinada mudanças significativas no trato com os percursos disciplinares escolares e acadêmicos, fundamentalmente no que se refere à prática e à discussão sobre a História ensinada.

O reconhecimento de que o ensino de História escolar se liga a campo das memórias (sociais/coletivas) sinalizou para a questão de que não somente existia historicidade no próprio ato da escrita histórica, mas que, igualmente, tornava importante"percebê-la como resultado de disputas entre memórias e como parte das lutas travadas nas sociedades pela atribuição de sentido a o passado"(GUIMARÃES 2003, p. 23). O conceito de cultura histórica tem permitido tratar historiograficamente com esta questão.

Esse conceito tem sido utilizado por historiadores, embora com nuances diferentes, para ampliar a percepção das diferentes formas e meios de representar o passado de uma sociedade. Para Jacques Le Goff, o conceito de cultura histórica pretende possibilitar uma contribuição a ideia de "usos" do passado. Consiste, em suma, nas maneiras de interpretação 
do passado, seus diferentes usos efetuados não só por historiadores, "[...] mas com todo um conjunto de fenômenos que constituem a cultura histórica, ou melhor, a mentalidade histórica de uma época". (LE GOFF, 1996, p.48)

Em sua obra História e Memória, Le Goff (1996, p.475) afirma que a memória tem como propriedade conservar certas informações, que não são ingênuas, mas se fazem e refazem a partir de interesses de grupos. Estudando o desenvolvimento da memória desde a Antigüidade, ele mostra que a

[...] evolução das sociedades na segunda metade do século XX clarifica a importância do papel que a memória coletiva desempenha. Exorbitando a história como ciência e como culto público, ao mesmo tempo a montagem enquanto reservatório (móvel) da história, rico em arquivos e em documentos/monumentos, e o aval, eco sonoro (e vivo) do trabalho histórico, a memória coletiva faz parte das grandes questões das sociedades desenvolvidas e das sociedades em vias de desenvolvimento, das classes dominantes e das classes dominadas, lutando todas pelo poder ou pela vida, pela sobrevivência e pela promoção.

Cultura histórica seria, portanto, parte dos processos sociais e coletivos de elaboração da experiência da passagem do tempo e das significações sociais do passado em que memória e história estão permeadas. Nessa discussão estão presentes, entre outras, as relações entre a produção do passado na sua forma acadêmica e na forma escolar. A forma escolar adquire relevância social uma vez que ultrapassa o âmbito de preocupações restritas aos especialistas, tornando-se uma reflexão mais ampla sobre as demandas por orientação no tempo e questionadora das relações entre história, memória e vida social, sobretudo nos significados políticos do uso da disciplina e, no desdobramento, sobre a formação de professores. Le Goff (1996, p. 48) afirma que um estudo dos manuais escolares de história é um aspecto privilegiado para se compreender a cultura histórica de uma sociedade.

Um dos aspectos fundamentais do conceito de cultura histórica para este artigo é que se reconhece atualmente o ensino de História como partícipe dos usos sociais do passado, bem como os seus nexos com a produção da memória coletiva e aos mecanismos sociais de sua reprodução. Nesse aspecto, história e memória são duas palavras que se relacionam nas muitas linguagens utilizadas para se referir ao tempo vivido e narrado. No entanto, "o enquadramento de ambos é distinto e a intenção de raiz de uma e de outra são diferentes, sendo a natureza da operação historiográfica crítica e analítica, enquanto é vivencial e 
testemunhal a raiz do artesanato da memória". (NEVES, 2009, p.26). Para Pierre Nora, memória e História também não são sinônimos, uma vez que para ele:

\begin{abstract}
A memória é a vida, sempre carregada por grupos vivos e, nesse sentido, ela está em permanente evolução, aberta à dialética da lembrança e do esquecimento, inconsciente de suas deformações sucessivas, vulneráveis a todos os usos e manipulações, suscetível de longas latências de repentinas revitalizações. A História é a reconstrução sempre problemática e incompleta do que não existe mais. A memória é um fenômeno sempre atual, um elo vivido no eterno presente; a história, uma representação do passado. (NORA, 1993, p. 9).
\end{abstract}

Compreende-se, então, que a memória se situa no terreno do "sagrado", das "tradições vividas" que constroem as identidades coletivas e individuais. A memória seria, como se entende, a experiência humana com o passado, recuperada por meio de lembranças da história vivida (memória individual) e/ou de histórias narradas (memória social) em uma dada temporalidade e relação social.

Refletir sobre os nexos entre cultura histórica e ensino escolar sugere que as sociedades cultuam suas memórias e que tais cultos são indicativos de uma identidade social - a ser reiterada ou construída - que naturaliza as tradições vividas na oposição à história que a problematiza e revisa.

Nesse aspecto, assinalar que a concepção de uma história escolar que trabalha com um tempo linear, cronológico, uma abordagem evolutiva e civilizacional, vinda da Europa ocidental, significa enfatizar que a ideia de progresso e civilização difundiu-se desde a colonização e quando a colônia tornou-se politicamente independente, parte da elite brasileira permaneceu com a configuração de poder representada por uma sociedade de corte, na qual o imperador, mantendo os privilégios da realeza, mantém igualmente os valores de diferenciação hierárquica entre os indivíduos e grupos sociais percebidos claramente na criação da imagem da nação e sua memória histórica.

A assimilação dessa memória, do pensamento civilizador sobre o passado colonizador, opera com a memória social e uma forma particular da memória coletiva da nação em uma sucessão de grandes temáticas iniciadas com o "Descobrimento". Memória que compõe a cultura histórica, em grande medida alimentada pela mídia, pela monumentalização de fatos e personagens, em diferentes narrativas sobre o passado nacional e que circulam em variados espaços de sociabilidades do país como, por exemplo, nos jornais, nos impressos de grande 
escala em geral, nas mídias eletrônicas, em imagens, comemorações cívicas, ciclos de conversas cotidianas e outros; uma cultura histórica que está presente no ensino por meio de "uma concepção de história que a aproxima da narrativa e da junção entre os elementos do meio e raça como explicativos da evolução dos povos". (NAXARA, 2000).

Lidar com a memória social, centralmente aquelas de elevada resistência à mudança e com claros traços de permanências das bases sociais, como é exemplar o tema "Descobrimento do Brasil", exige que se considere a cultura história apresentada nitidamente na prática social dos alunos, sua experiência com a memória coletiva, identificando aspectos mais enraizados que se mantêm presentes sobre o momento histórico em questão e discutilos em sua própria tradição que muitas vezes se mantém no ensino escolar independente da produção acadêmica.

Atribuir sentido ao passado parece ser um mote normativo para a Didática da História se a considerarmos instância organizadora do trabalho pedagógico escolar. Para ela, impõe-se, neste cenário, um conjunto de problematizações que leve em conta o trajeto de disciplinarização da história escolar e os "entrelaçamentos entre projetos de escrita sistemática das lembranças do passado e a produção da memória social", eixo de construção de sentidos sobre o passado que se ensina. (GUIMARÃES, 2000, p. 22-23).

Reconhecer que a qualidade e coerência do que os alunos sabem sobre a história são determinadas por seu desenvolvimento cognitivo e por suas experiências de aprendizagens escolares bem como pelas influencias culturais que recebem, para além da instituição escolar, implica em considerar as condições de produção de saber escolar e os "usos sociais" do passado pela maneira como a forma escolar dialoga, interage, com outros espaços/lugares de produção de saberes históricos e, historiograficamente, implica em considerar a dimensão epistemológica da história e seu ensino, com o fim de melhor situar a memória e dela fazer uso, mas, sobretudo, problematizá-la. O que remete a reflexão sobre questões de epistemologia tal como se compreende hoje, espaço de crítica, rigor metodológico e narrativa problematizadora.

\section{Epistemologia da história e ensino escolar: algumas questões}

A Didática da História mantém uma complexa relação situada entre o esforço de produzir sentido para o passado no ensino escolar e, ao mesmo tempo, de se fundamentar teoricamente 
no campo específico de construção de conhecimentos históricos, na historiografia e na epistemologia da história.

No que se refere às relações sobre epistemologia, pode-se assinalar que uma das razões seria para que o ensino de História não se torne inócuo diante da necessidade premente de possibilitar leituras do passado por meio de textos ou conjunto de textos didáticos. O que implica em ser uma forma específica de organizar a experiência do aprender e ensinar sobre o tempo por meio de um conjunto reflexivo sobre: o passado/presente, seus indícios/fontes, sujeitos/grupos, sociedades/comunidades, espaços, relações, conceitos, narrativas.

O aspecto epistemológico vincula-se fortemente às teorias da história, nas possibilidades de concepção/compreensão da história existentes que orientam e são aceitas pelos historiadores em determinado tempo e lugar. Sobre isso, pensa-se que são marcantes as mudanças que se processaram no campo da produção historiográfica brasileira em fins do século XX para se compreender o debate epistemológico em que este ensino está inserido contemporaneamente.

Sobre isso, é importante mencionar que os contornos da produção historiográfica brasileira se tornam, na segunda metade do século passado, mais abertos no que se refere a procurar renovações teóricas e metodológicas motivadas, inicialmente, por autores franceses que ficaram conhecidos por iniciarem publicações críticas de seus estudos na revista chamada Annales, mais especificamente Marc Bloch (1886-1944) e Lucien Febvre (1878-1956).

Michael Roberts (2011) escrevendo sobre a revista Annales observa que seus objetivos iniciais eram sublinhar enfaticamente suas diferenças com relação a uma geração anterior, a primeira de historiadores franceses profissionais na França, para justificar o novo empreendimento teórico de amplo aspecto, realizados por meio de publicações, críticas de livros e do estabelecimento de cátedras universitárias. Para Roberts, esse momento consolida a crítica metodológica do pensamento histórico moderno, anunciando uma abordagem do passado que poderia "colocar o sentimento nacional em seu devido lugar e explorar aquelas experiências extranacionais de grande escala que definiram a Europa e sua civilização" (ROBERTS, 2011, p.106), uma história que fosse social, econômica e acolhesse estudos interdisciplinares. Do ponto de vista da prática historiográfica, o principal problema para aqueles autores residia "na definição de um método científico suficientemente rigoroso pelo qual se pudesse entender a experiência humana no tempo". (ROBERTS, 2011, p.103, grifo nosso).

Tal projeto redefine o entendimento da importância do conhecimento histórico, construindo novas possibilidades interpretativas e abrindo discussões de amplo fôlego para pensar probabilidades de pesquisas. Febvre, por exemplo, a o considerar que a história deveria ter como objeto de estudos não "um fragmento do real, um dos aspectos isolados da actividade humana - mas o próprio homem, entendido no seio dos grupos de que faz parte" (FEBVRE, 1989, p. 31), desloca o sentido e redefine o conceito de história e as maneiras de estudá -la; assim 
como Bloch, para quem a história não era a ciência do passado, mas, sim, "a ciência dos homens no tempo" (BLOCH, 2001).

Considerada nesses termos, a história passaria a ter como principal questão a experiência humana no tempo e a definição de um método científico que pudesse compreender e explicar tal experiência em sua riqueza e complexidade. Com esse cenário, Fernand Braudel (1902 1985), sucessor dos pioneiros na revista, concluía: "das experiências e tentativas recentes da história, desprende-se - consciente ou não, aceita ou não - uma noção cada vez mais precisa da multiplicidade do tempo e do valor excepcional do tempo longo"(BRAUDEL, 1965, p.263).

Braudel destacou a importância de pautar e relacionar as durações e os ritmos temporais pelos quais a história se faz (do acontecimento, da conjuntura e da estrutura) para melhor se compreender a complexidade dos fios relacionais, postos em movimentos pela ideia de permanência, continuidade e rupturas. A compreensão da relação passado/presente, da temporalidade, dos recortes temáticos, da compreensão de documentos históricos e fontes, ou seja, as questões de epistemologia da história vieram se redefinindo desde então.

Entende-se que a questão epistemológica apresentada pelos Annales reside exatamente no enfrentamento de uma concepção da história então predominante no século XIX não apenas na França, que Henri Berr chamou de história historizante. Febvre procedeu a crítica em seus "combates" no texto de 1947, Sur une forme d'histoire qui n'est pás la nôtre. L'histoire historisante, no qual indaga:

Que será, com efeito, um historiador historizante? Henri Berr, [...], respondia em substância: é um homem que, trabalhando sobre fatos particulares estabelecidos por ele próprio propõe-se a ligar entre si tais fatos, coordená-los e em seguida "analisar as mudanças políticas, sociais e morais que os textos nos revelam em um dado momento". As mudanças particulares, entenda-se [...] a história se define como uma ciência do particular. (FEBVRE, 1992, p.104).

A problemática epistemológica está descrita, em suas questões básicas, nessa indagação que faz transparecer a organização teórica, constituída de finalidade, metodologia e objeto da história como ciência tal como é realizada pela história historizante. Febvre expõe sua crítica exatamente no caminho traçado: "estabelecer inicialmente os fatos, colocá -los em seguida em ação", definindo os procedimentos nas seguintes etapas: I. O estabelecimento dos fatos; II. A coordenação dos fatos; III. A exposição dos fatos. Para essa concepção, a possibilidade de 
pesquisar o passado estaria nesse exercício que Febvre continua problematizando: "E a que denominam vocês fatos? Que colocam vocês atrás dessa pequena palavra, 'fato'?". E segue:

\begin{abstract}
Pensam acaso que eles [fatos] são dados à história como realidades substanciais, que o tempo escondeu de modo mais ou menos profundo, e que se deve simplesmente desenterrar, limpar e apresentarà luz do dia aos nossos contemporâneos? (FEBVRE, 1992, p.105).
\end{abstract}

O historiador francês trata da questão da origem do conhecimento histórico, a quem a história historizante responde ser dos "fatos". Sua natureza como conhecimento específico estaria em apresentar os "fatos" como realidades extraídas das fontes. Sua finalidade estaria em apresentar o passado e seus testemunhos em exposição factual explicativa do passado. Desse trajeto surgiria a história. Metodologia que Febvre ataca veementemente sugerindo que tal procedimento resultava num entendimento de que a história seria "revelada", "no sentido fotográfico do termo". Ao passo que, para os historiadores dos Annales, "é o historiador que os forja. Não é, como ele diz, 'o Passado'. Ou, por uma estranha tautologia, 'a história'”.

Ora, sem teoria prévia, sem teoria preconcebida, não há trabalho científico possível. [...]. De uma ciência que não tem como último objeto descobrir leis, mas sim possibilitar-nos a compreensão. Toda teoria é naturalmente fundada sobre este postulado de que a natureza é explicável. E o homem, objeto da história, faz parte da natureza. Ele é a história o que a rocha é para o mineralogista, o animal para o biólogo, a estrela para o astrofísico: algo a ser explicado. A tornar compreensível. $\mathrm{E}$ portanto a pensar. Um historiador que se recusa a pensar sobre o fato humano, um historiador que professa a submissão pura e simples a esses fatos, como se não fossem de sua fabricação, como se não tivessem sido escolhidos por ele, previamente, em todos os sentidos da palavra "escolhido" - é uma ajuda técnica. Que pode aliás ser excelente. Mas não é um historiador. (FEBVRE, 1992, p.106).

Para os autores franceses, o objeto da história não mais seria o indivíduo, o personagem singular e seu feito, mas todos os homens e suas experiências como seres sociais, organizados em grupos; o tempo cronológico seria uma das experiências humanas com o passado, era necessário prestar atenção a todas as possibilidades temporais da vivência social. A 
linearidade que justificava a sequência e ordenação dos fatos do tempo progressivo seria seriamente questionada. Por isso esses historiadores diziam, no século $\mathrm{XX}$, que faziam "combates pela história", afirmando que a história era uma "ciência em construção", porém com a certeza de que não seria mais, conforme Pierre Vilar(1985), "[...] curiosidade ou nostalgia do passado, coleção de imagens sedutoras ou gloriosas, mas desejo de um conhecimento explicativo, útil para o presente". Uma história -problema.

Para os autores dos Annales, portanto, a história é um conhecimento mediado por uma teoria, cujo suporte é o material histórico expresso nos vestígios do passado coletados e selecionados pelo historiador tendo por princípio um tema e um problema a ser investigado.

[...] Mas que é enfim a história? Vou dizer-lhe. Você recolhe os fatos. Para isso você vai aos Arquivos. Esses celeiros de fatos. Lá, basta você se abaixar para recolhê-los. Encha com eles os seus cestos. Limpe-os bem da poeira. Coloque-os sobre a sua mesa. Faça como as crianças, quando se divertem com os "cubos" e trabalha para reconstituir a bela imagem que foi mostrada e depois destruída... O lance está feito. A história também. Que mais quer você? - Nada. A não ser: saber por quê. Por que fazer história? E, portanto, que é a história? (FEBVRE, 1992, p.107).

Por intermédio da crítica ao que compreendiam ser uma história historizante irão construir aportes teóricos para se pensar a relação entre a história e sua escrita, localizando o conceito de tempo como eixo ao redor do qual se pesquisa, escreve e narra o passado da experiência humana.

Por meio das críticas a historia historizante, os Annales possibilitaram, ainda, que uma Nova História francesa pudesse se firmar apresentando "novos objetos", "novos horizontes", "novos problemas", em fins do século passado, como recursos para enfrentar as dificuldades de análises que encontravam para conhecer as experiências históricas das diferentes sociedades sob novos procedimentos. Mudanças epistemológicas que atingiram, nas últimas décadas do século $\mathrm{XX}$, a historiografia brasileira e causaram impactos nas buscas por mudanças nas discussões sobre a História escolar. Um dos impactos mais visíveis foi o trato com a categoria de tempo histórico. Pensar sobre o tempo na História passou a ser:

[...] compreender que as noções que construímos sobre tempo, inclusive quanto ao seu caráter cíclico e renovador, são representações elaboradas por homens e mulheres de diferentes épocas, a partir de determinados 
contextos e necessidades. É identificar o "saber" que temos sobre o tempo e entender porque tal saber se constituiu a partir de determinados referenciais explicativos para a realidade. (OLIVEIRA, 2010, p. 37).

A compreensão de que o tempo é, ele mesmo, histórico, ou seja, apresenta mudanças e diferenças sobre o seu significado e o papel que lhe foi atribuído em diferentes sociedades permite, inicialmente, que se reconheça que a temporalidade é uma construção social e não um dado "puro" a ser resgatado do passado - como queria a historia historizante; mas exige do historiador atividades operacionais complexas para delimitar, definir, selecionar, analisar e explicar um acontecimento.

Nesse aspecto, entende-se que a história oficial prolongou, por meio da memória que constrói, passados particulares com que se pretendeu legitimar posições de grupos e indivíduos posicionados de forma diferente e desigual na sociedade, perpetuando o passado (e o presente) vividos. Basta pensar a importância e o significa do que as comemorações cívicas tiveram/têm para a memória coletiva e a manutenção da temporalidade com dimensão cronológica, linear e centrada numa história política voltada para a "evolução" da nação.

A importância da discussão epistemológica reside, portanto, na problematização da história que se produz e se ensina como núcleo central da representação social sobre o passado que continuam a ecoar nos tempos, as ideias, conceitos, imagens, temas, narrativas, que dão sustentação a sua manutenção na cultura escolar.

Retomando os problemas apontados sobre a disciplinarização da história, tratados no inicio deste artigo, em sua relação com a formação social brasileira, o texto de Miguel Vale de Almeida, escrito na ocasião da comemoração dos 500 anos do descobrimento do Brasil, é sugestivo para se pensar a análise e a importância do questionamento da memória social produzida e da revisão historiográfica na atualidade. Sobre a questão das etnias ele afirma:

No processo de construção da nacionalidade brasileira, três problemas fundamentais foram sendo (ir)resolvidos: o da expansão e consolidação territorial, com o extermínio ou submissão das populações indígenas; o da escravatura, sua abolição, e integração das populações afrodescendentes; e a imaginação da nação como idealmente branca ou realisticamente miscigenada - tendo esta característica sido concebida, primeiro, como negativa e, posteriormente, como positiva. (ALMEIDA, 2005, p.128, grifos meus). 
Como o texto exemplifica, compreender requer a síntese e tomada de consciência das razões e posições dos atores sociais expressas numa complexa vivência de relações de trabalho, culturais e de poder. De forma que o processo explicativo só se realiza se incluir nos tempos e nos espaços uma dimensão compreensiva dos acontecimentos, com recurso à compreensão de comportamentos individuais e coletivos e à compreensão da vivência, pelo próprio historiador, da experiência histórica narrada. O que significa dizer, com os Annales, que, epistemologicamente, não se trata apenas de informar um fato, ou sucessão de acontecimentos, uma cronologia, mas de problematizar a memória social e realizar o esforço de ler temporalmente os muitos problemas sociais ainda não resolvidos, o que faz notar com clareza o quanto presente e passado estão vinculados.

Na comparação com as orientações da história historizante, não se trata de proceder ao encaminhamento: I. O estabelecimento dos fatos; II. A coordenação dos fatos; III. A exposição dos fatos. Mas, trata-se de proceder a uma construção que não se move nesse ritmo linear, mas por uma "arquitetura complexa", para usar o termo do filósofo francês Paul Ricouer (2003). Isso porque:

A interpretação não é uma fase à margem do conjunto da operação histórica; pelo contrário, ela trabalha a todos os níveis, desde o estabelecimento do testemunho e dos arquivos até à explicação em termos de finalidade ou de causalidade, desde a esfera da economia à da cultura. (RICOEUR, 2003, p.5).

Reafirma-se, portanto, que é preciso ter um problema, proceder aseleção de fontes, leituras, análises - duração, jogo de escalas - crítica documental, elaborar uma narrativa/explicação que leva em conta a multifacetada dimensão temporal das durações e as demais temporalidades, como propõe Braudel (1965).

Como se reconhece atualmente, o ofício do historiador se faz fundamentalmente por meio da escrita. Por intermédio da escrita e da leitura chega-se na narrativa, o que permite ao historiador "fornecer uma legibilidade ao texto e uma visibilidade aos eventos que narra, por vezes, em detrimento da complexidade e da opacidade do passado histórico". (RICOEUR, 2003, p. 6). Michel De Certeau (1925-1986) remete essa complexidade da construção do objeto histórico à ideia de "operação historiográfica". Tal operação resulta das vivências do profissional da História, na qual suas escolhas perpassam o texto assim como o lugar social no qual está inserido. 
[...] o historiador tem 'o tempo' como 'material de análise' ou como 'objeto específico'. Trabalha, de acordo com os seus métodos, os objetos físicos (papéis, pedras, imagens, sons, etc.) que distinguem, no continuum do percebido, a organização de uma sociedade e o sistema de pertinências próprias de uma 'ciência'. Trabalha sobre um material para transformálo em história". (CERTEAU, 2006, p.79).

Certeau permite relacionar as dimensões do oficio do historiador e do professor de História ao pensar nos nexos entre um lugar social de produção, uma prática operacional, um texto e uma forma narrativa como resultados do ofício e da formação profissional. A operação historiográfica produzida pelo historiador é análoga à organização do trabalho pedagógico do professor por dois motivos centrais: eles se realizam tendo o tempo como objeto e conceito específico, trabalham subsidiados por métodos operacionais, estão submetidos à forma como a sociedade atribui relevância social ao passado, relacionam-se com a memória, acontecem num lugar social de produção.

Toda pesquisa historiográfica se articula com um lugar social de produção sócio-econômico, político e cultural. Implica um meio de elaboração que circunscrito por determinações próprias: uma profissão liberal, um posto de observação ou de ensino, uma categoria de letrados, etc. Ela está, pois, submetida a imposições, ligada a privilégios, enraizada em uma particularidade. É em função deste lugar que se instauram os métodos, que se delineia uma topografia de interesses, que os documentos e as questões, que lhes serão propostas, se organizam. (CERTEAU, 2006, p.66-67, grifo meu).

A escrita da História faz parte de uma prática social que se realiza em um lugar social. A escola, como espaço de sociabilidades e instituição de ensino, produz uma escrita voltada e submetida à imposição desse lugar, por meio das práticas que visam ensinar uma História particular, a escolar. Ao enunciar que em história tudo começa com "o gesto de separar, de reunir, de transformar em 'documentos' certos objetos distribuídos de outra maneira”, Certeau permite que se pense a prática do professor na instituição de ensino como uma elaboração profissional. Pois, não seria isso que o professor inicialmente realiza quando está preparando, organizando, sistematizando seu trabalho pedagógico? 
De forma relacional, a independência e as proximidades da operação historiográfica acadêmica e escolar se realizam nas formas como ocorrem a operação historiográfica e sua finalidade social. Elas se aproximam ou se distanciam segundo a maneira como a operação historiográfica se estabelece e sua pertinência epistemológica de construção de conhecimento/saber sobre o passado. Os lugares sociais de produção são diferentes (academia/escola), onde estão também situados diferentemente o "fazer" e a relação com o saber histórico. Entretanto, epistemologicamente, o movimento de produção do saber escolar se apropria da operação historiográfica acadêmica (conceitos e referenciais teóricos) estabelecendo relações operacionais, mas, ao mesmo tempo, situando-as em outro lugar de produção que é a escola, o que demanda uma nova lógica explicativa do passado.

Ora, compreender o ensino de história escolar como uma operação historiográfica que se realiza num lugar social em que se processam formas de aprendizado sobre significar o passado não seria uma referência para a Didática da História?

De forma relacional, a independência e as proximidades da operação historiográfica acadêmica e escolar se realizam nas formas como ocorrem a operação historiográfica e sua finalidade social. Elas se aproximam ou se distanciam segundo a maneira como a operação historiográfica se estabelece e sua pertinência epistemológica de construção de conhecimento/saber sobre o passado. Os lugares sociais de produção são diferentes (academia/escola), onde estão também situados diferentemente o "fazer" e a relação com o saber histórico. Entretanto, epistemologicamente, o movimento de produção do saber escolar se apropria da operação historiográfica acadêmica (conceitos e referencia is teóricos) estabelecendo relações operacionais, mas, ao mesmo tempo, situando-as em outro lugar de produção que é a escola, o que demanda uma nova lógica explicativa do passado.

Compreender o ensino de história escolar como uma operação historiográfica que se realiza num lugar social em que se processam formas de aprendizado sobre significar o passado não seria uma referência para a Didática da História? Ciampi (2003, p.111-112), ao mencionar tais elementos indica:

A partir de um problema levantado sobre os dados colocados pelas vozes dos diferentes sujeitos, nas fontes investigadas, o historiador constrói sua interpretação. Assim, também, o professor deve pensar, um problema a ser trabalhado com os seus alunos. Ao pensar o que fazer em Lima série, é fundamental selecionar um tema e os assuntos que lhe permitam analisar/responder a problemática escolhida. Ressaltar os desdobramentos do ofício do historiador no trabalho do professor em sala de aula, bem como a preocupação com montagem do tema, a problematização, o trabalho de seleção, tratamento e confronto das 
fontes para compreensão e explicação do objeto de estudo. Ter o aluno e o professor como sujeitos históricos e do seu próprio conhecimento.

Compreende-se que a Didática deve participar do debate sobre o campo disciplinar e epistemológico da história, sobre questões relativas à memória, sobre os usos do passado e a cultura histórica, contribuir, enfim, com a normatização da operação historiográfica escolar. É nesse eixo referencial que ela tem se justificado atualmente como conhecimento necessário ao professor do ensino básico e sua aprendizagem desde os anos iniciais do ensino fundamental.

\section{Considerações finais:}

Nos últimos tempos, têm sido crescente os debates sobre o papel social da história e de seu ensino com as problemáticas sociais, em especial as demandas memoriais e a difusão do conhecimento histórico por meio de uma história pública. Este debate, ao enfatizar a cultura histórica que está presente como permanência na sociedade brasileira, anuncia a importância de discutir amplamente a história como ofício, ou seja, como campo disciplinar que é produzida, necessariamente, por historiadores de ofício e, no âmbito escolar, pelos professores de História. Neste sentido, a discussão sobre a Didática da História se movimenta em torno dos nexos: aprender e ensinar História na articulação historiográfica com a cultura histórica produzida socialmente.

Ao lidar com essa questão, o artigo pontuou dois aspectos que considera central para o trato com o problema: a dimensão disciplinar da História escolar e seu caráter integrador da cultura histórica da sociedade brasileira. Quanto ao primeiro aspecto, enfatizou que a disciplinarização da história proclama a identidade e soberania do país, uma tradição a ser lembrada pelos cidadãos por meio de uma memória social sobre o passado no qual estão justificados, de antemão, os posicionamentos dos grupos sociais na arena política e social. E, quanto ao segundo aspecto, sinalizou que o estudo da memória se torna essencial para a problematização dessa representação social da história escolar. Afirma que a memória se situa no terreno do "sagrado", das "tradições vividas" que constroem as identidades coletivas e individuais. A memória seria, então, a experiência humana com o passado, recuperada por meio de lembranças da história vivida (memória individual) e/ou de histórias narradas (memória social) em uma dada temporalidade e relação social. Por esse caminho, refletir sobre os nexos entre cultura histórica e ensino escolar assinala que as sociedades cultuam 
suas memórias e que tais cultos são indicativos de uma identidade social - a ser reiterada ou construída - que naturaliza as tradições vividas na oposição à história e a historiografia que a problematiza e revisa.

A procura por mudanças na epistemologia da história pode contribuir significativamente para pensar a Didática da História num contexto de busca por explicitar o esgotamento de um projeto de ensino que, fundado no século XIX, acreditava poder reproduzir fielmente o passado em unidades didáticas, levando professores e alunos a reafirmarem a memória histórica da nação. Uma memória que, na perspectiva de um Brasil que buscava se integrar à civilização ocidental, criou muitos mitos sociais, como: o mito da passividade do povo, o mito da inferioridade do índio e do negro, o mito da cordialidade do homem brasileiro, o mito da democracia racial, entre outros. Importantes aspectos da memória social que, conforme Diehl (1998, p. 94), fazem parte até hoje da consciência histórica e da autoimagem de homens e mulheres brasileiros. Questão que envolve o problema histórico central da relação entre ensino de História e os "usos" sociais do passado, da história escolar e a circulação de saberes históricos em diferentes esferas de sua produção na sociedade brasileira.

Por fim, retomando a epígrafe que abre este artigo, assim como o garoto que pergunta ao pai sobre a serventia da história, a sede de saber que envolve as crianças e jovens das escolas públicas brasileiras deve ser instigada, anunciada, valorizada, pois "o problema que ela coloca, com a incisiva objetividade dessa idade implacável, não é nada menos do que o da legitimidade da história". (BLOCH, 2001, p.41).

\section{Referências}

ALMEIDA, Miguel Vale de. Comemoração, nostalgia imperial e tensão social - o desenvolvimento Portugal-Brasil: comentários às análises de imprensa. In: SÁ, Celso P.; CASTRO, Paula.(Org.). Memórias do Descobrimento do Brasil. Rio de Janeiro: Museu da República, 2005.

ASSIS, Arthur. A teoria da história de Jörn Rüsen: uma introdução. Goiânia: UFG, 2010.

BARBOSA, Januário da Cunha. Extrato dos Estatutos. Revista do IHGB, Rio de Janeiro, v. 1, p.18$19,1839$.

BLOCH, Marc. Apologia da História, ou o Oficio do Historiador. Rio de Janeiro:Jorge Zahar, 2001. 
BRAUDEL, Fernand. A história e as Ciências Sociais: a longa duração. Revista de História, São Paulo, ano 16, v. 30, n. 62, p. 261-294, abr.-jun. 1965.

BURKE, Peter. História com memória social. In: Variedades de História Cultural. Rio de Janeiro: Civilização brasileira, 2000.

CASTRO, Paula. Hegemonia e polêmica na memória social do descobrimento do Brasil. In.: SÁ, Celso P.; CASTRO, Paula.(Org.). Memórias do Descobrimento do Brasil. Rio de Janeiro: Museu da República, 2005.

CERRI, Luis Fernando. Os conceitos de consciência histórica e os desafios da didática da história. Revista de História Regional. Ponta Grossa, v.6, n.2, p.93-112, 2010.

CERTEAU, Michel De. A escrita da história. 2. ed. Rio de Janeiro: Forense Universitária, 2006.

CHESNEAUX, Jean. Devemos fazer tábula rasa do passado? São Paulo: Ática, 1994.

CIAMPI, Helenice. O processo do conhecimento/pesquisa no ensino de história. História $\mathcal{E}$ Ensino, Londrina, v. 9, p. 109-132, out. 2003.

DIEHL, Astor Antônio. A cultura historiográfica brasileira: do IHGB aos anos1930. Passo Fundo: Ediupf, 1998.

ELIAS, Norbert. A sociedade de corte: investigação sobre a sociologia da realeza e da aristocracia de corte. Rio de Janeiro: Jorge Zahar, 2001.

FEBVRE, Lucien. Profissões de fé à partida. In: . Combates pela história. Lisboa: Editorial Presença, 1989.

- - _ _. Combates. In: MOTA. Carlos Guilherme (Org.). Febvre. História. São Paulo: Ática, 1992. (Coleção Os grandes Cientistas Sociais).

GASPARELO, Arlette M. Construtores de identidades: a pedagogia da nação nos livros didáticos da escola secundária brasileira. São Paulo: Iglu, 2004,

GUIMARÃES, Manoel Luiz Salgado. Repensando os domínios de Clio: as angústias e ansiedades de uma disciplina. Revista Catarinense de História, Florianópolis, n. 5, p. 5-20, 1998. . Usos da história: refletindo sobre identidade e sentido. História em Revista. Pelotas/RS, v. 6, p. 21-36, 2000.

_. _ _ _. A cultura histórica oitocentista: a constituição de uma memória disciplinar. In: PESAVENTO, Sandra J.(Org.). História cultural: experiências de pesquisa. Porto Alegre: Editora da Universidade/UFRGS, 2003. p. 9-24. 
HALBWACHS, Maurice. A memória coletiva. Tradução de Beatriz Sidou. São Paulo: Centauro, 2006.

HOBSBAWM, Eric; RANGER, Terence. A invenção das tradições. 6. ed. Rio de Janeiro: Paz e Terra, 1997.

LE GOFF, Jacques. História e memória. Tradução Bernardo Leitão. 4. ed. Campinas, SP: Unicamp, 1996.

LIMA, Maria. Consciência histórica e educação histórica: diferentes noções, muitos caminhos. In: MAGALHÃES, Marcelo et al. (Org.). Ensino de História: usos do passado, memória e mídia. Rio de Janeiro: Ed. FGV, 2014.

MARTIUS, Carlos Frederico P. von. Como se deve escrever a história do Brasil. In: .$O$ Estado do Direito entre ao autóctones do Brasil. São Paulo: Ed. Itatiaia/EDUSP, 1982.

NAXARA, Márcia Regina Capelari. Pensando Origens para o Brasil no Século XIX: História e Literatura. História: Questões \& Debates, Curitiba, n. 32, p. 47-64, jan./jun., 2000.

NEVES, Margarida de Souza. Nos compassos do tempo. A história e a cultura da memória. In: SOIHET, Rachel et al. (Org.). Mitos, projetos e práticas políticas: memória e historiografia. Rio de Janeiro: Civilização Brasileira, 2009.

NORA, Pierre. Entre Memória e História: a problemática dos lugares. Projeto História: revista do Programa de Estudos Pós-Graduados em História e do Departamento de História da PUC/São Paulo, São Paulo, n. 10, p. 7-28, dez., 1993.

OLIVEIRA, Sandra Regina F. de. Os tempos que a história tem. In.: OLIVEIRA, Margarida Maria Dias de. (Org.). História: ensino fundamental. Brasília: MEC, Secretaria de Educação Básica, 2010. p.35-58.

RICOEUR, Paul. Memória, história, esquecimento. 2003. Disponível em: http://www.uc.pt/fluc/lif/publicacoes/textos_disponiveis_online/pdf/memoria_historia. Acesso em: 9 jun. 2016. Título original Memory, history, oblivion.

ROBERTS, Michael. E Escola dos Annales e a escrita da História. In: LAMBERT, Peter et al. História: introdução ao ensino e à prática. Tradução Roberto Cataldo Costa. Porto Alegra: Penso, 2011.

SCHMIDT, Maria Auxiliadora História com Pedagogia: a contribuição da obra de Jonathas Serrano na construção do código disciplinar da História no Brasil. Revista Brasileira de História, v. 24, n. 48, p. 189-211, 2004. 
TOLEDO, Maria Aparecida LeopoldinoTursi. A história ensinada sob o império da memória: questões de História da disciplina. História [online], São Pulo, v.23, n.1-2, p.13-32, 2004.

_. _ _ _. Pensar a história, repensar seu ensino: por que ensinar o passado à infância brasileira?. In: AMARO, Hudson Siqueira; RODRIGUES, Isabel Cristina. (Org.). História: metodologia do ensino. 2. ed. Maringá: EDUEM, 2012. v. 1, p. 19-40.

_ - _ _ _ . Problema tizar o tradicional para encontrar o novo: o ensino de História no quadro das tendências historiográficas. Cadernos de História da Educação, Uberlândia, v.15, n.1, p.323347, jan.-abr. 2016.

VARNHAGEN, Francisco Adolpho de. Historia Geral do Brazil.. Rio de Janeiro: Caza de E. e H. Laemmert, 1854. t. 2.

VILAR, Pierre. Iniciação ao vocabulário de análise histórica. Lisboa: Sá da Costa, 1985.

Recebido em 05.07.2016

Aprovado em 03.10.2016 